\title{
دروس مستفادة من رواقية ماركوس أوريليوس
}

\section{د. عبد العزيز إمام محمود}

\section{جامعة مصراتة}

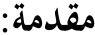

يتناول هذا البحث بعض الدروس التي يمكن للفرد الاستفادة منه من خلال فلسفة

$$
\text { الإمبراطور ماركوس أوريليوس، وهي التي توضح صورة الفكر في عصره. }
$$

كان أبرز تيارات الفلسفة في القرن الثاني الميلادي، الفلسفة الرواقية التي جاء اسمها

نسبة إلى الرواق المنقوش الذي كانت أعمدته مزدانة بنقوش من ريشة الرسام بوليجنوتوس(*)

Diogenes Laertius ${ }^{(*)}$ Polygnotus

في كتابه " حياة الفلاسفة البارزين" أن زينون(1) كان يقوم بالتدريس في هذا الرواق(2). كان زينون أول من قام بتعليم مبادئ الرواقية حوالي سنة "300 ق.م" وكانت هذه الفلسفة في سماها أكثر تدينا من أي فلسفة يونانية أخرى، جاءت للعالم بقوة أخلاقية جديدة ووضعت التأمل العقلي خلفية لها وجاءت بوجهة نظر أخلاقية للفلسفة الكلبية في السيطرة على السلوك القويم. ومرت الفلسفة بمراحل عديدة على مر العصور. وقسم المؤرخون المذهب الرواقي إلى ثلاثة عصور كبرى: - (1)

** بوليجنوتوس هو رسام يوناني عاش أوائل القرن الخامس قبل الميلاد ولد بجزيرة Thasos وعاش في أثينا.

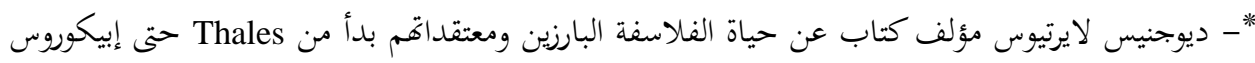
Epicurus ، يقال إنه عاش في النصف الأول من القرن الثالث الميلادي.

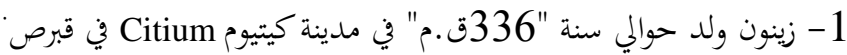

2- Diogenes Laertus, Vitae philosophorum; book 7. section 5. line 5 to Vit. 7. 5. 7 
أولا. الرواقية القديمة؛ وتبدأ مدقا من "322 - 204 ق.م"، وأقطاب هذه الفترة هم

زينون وكليانثيس (*) من أسوس Cleanthes. ثانيا. الرواقية الوسطى؛ وتبدأ من القرن الثاني حتى القرن الأول قبل الميلاد، ومن أشهر

أتباعها بانايتيوس (*) Panaetius. ثالثا. الرواقية الحديثة؛ وتبدأ من القرن الأول الميلادي حتى عام "529 بعد الميلاد"،

وأهم أقطاب هذه الفترة من الرومان هم لوكيوس أنايوس سينيكا(*) Seneca على الرغم من أن أصل الرواقية برهن على تبني الشخصية الرواقية العملية فقد شكلت الرواقية حصنا منيعا لحرية الرومان في ظل حكم القياصرة المستبدة، حيث لا تؤثر النار ولا الحديد ولا التدنيس في أي شيء حيث تستمر الأمور في سيرها بلا تغيير(1)، وأن ما يسيطر على الفرد من متع لا يمكن قهرها، ولكن عندما يتشبع الفرد من كل المتع الممكنة، يمكنه عدم فعل الشيء الذي لا يريده (2).

** كليانثيس فيلسوف رواقي ولد سنة "331ق.م" وكان مصارعا.

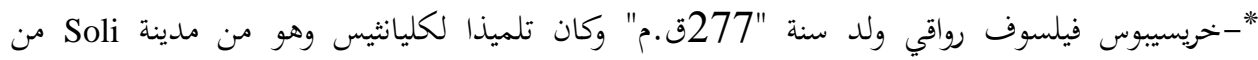
.Tarsus * - بانايتيوس فيلسوف رواقي ولد سنة "180ق.م" وألف كتاب "العناية" وكتاب " الرغبة" وكتاب

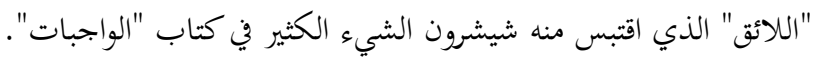

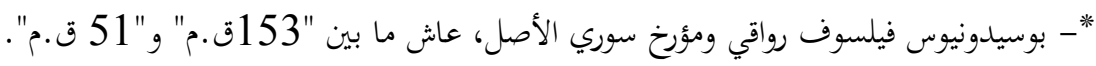

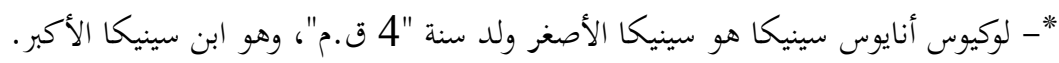

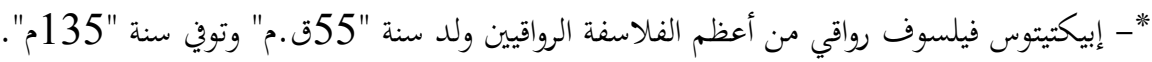

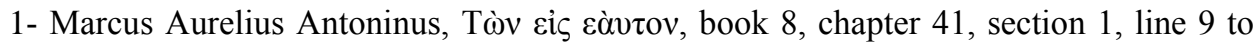
10.

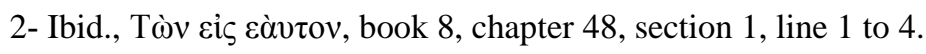


وقد وصلت الرواقية أوج عظمتها ووجدت مكوناتما السامية معتقدا حيا عند سينيكا

والعبد الفيرجي إبيكتيتوس والإمبراطور ماركوس أوريليوس، الذي يفهم منه أن الفلسفة الرواقية

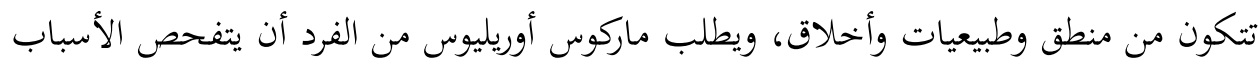
والظواهر الطبيعية ويحلل عواطفه وأن يكون ماهرا في البحادلات المنطقية. (1) ويذكر إبيكتيتوس أنه بالمنطق يكون لدى الفرد القدرة على التمييز وفحص كل ولى الأشياء

الأخرى لقياس ووزن هذه الأشياء بالجدل والبلاغة ويعتبر المنطق أداة ضرورية للتأمل (2).

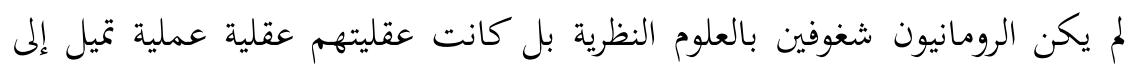
النظام والحكومة والقانون، وتحردت الفلسفة الرواقية من المنطق القديم الذي كانت سمته الرئيسة هي اللباقة والالتفاف حول الأمور، ولم يعد أحد يذكر فلسفة المنطق والطبيعيات إلا فيما ندر. يتضح هذا من خلال رأي سينيكا في كتابه "الأسئة الطبيعية" Naturales Quaestiones حيث يزدري علم المنطق ويمر إبيكتيتوس مرور الكرام على المسائل الطبيعية، أما ماركوس أوريليوس فلم يتحدث عنها بشيء (3). وأصبحت الفلسفة الرواقية لدى الرومان فنا جديدا يتسم بالمرونة وتحليل طبيعة الإنسان

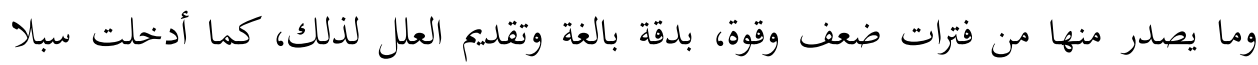
جديدة لمعالجة أمراض النفوس ونظرت نظرة واقعية في مختلف مراتب الكمال ووسائل بلوغها، أبرزت شعورا دينيا يعبر عن مطامح البشر وهواجسهم. هكذا أصبح الرواقي في روما مرشدا وهاديا بعد أن كان في أثينا معلما أو مدرسا، فلم يقبل على سينيكا من التلاميذ والمريدين إلا طائفة يختارة يبوحون له بجميع شؤوهم وخلجات نفوسهم فيرفض ما عملوا ويسدي إليهم

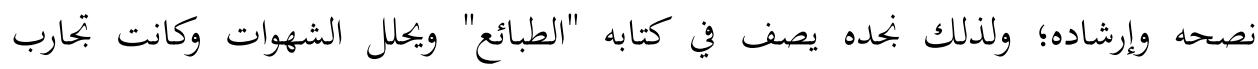
الفيلسوف الشخصية في الحياة وصلاته بالناس في زمانه هي مصادر مكتسباته الفلسفية، ولقد

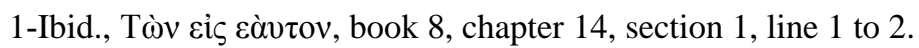

2-Epictetus Phil., Dissertationes ab Arriano digestae, Book 1, chapter 17, section 10, line 2 to section 11 , line 1 .

$$
\text { 3- عثمان أمين، الفلسفة الرواقية، القاهرة، 1945م، ص } 176 .
$$


انتشر المرشدون والهداة من الرواقيين في المدن الرومانية فضلا عمن كانوا معروفين من الرواقيين الكبار وكان هؤلاء الأساتذة يؤدون مهمتهم في نشر الأخلاق الرواقية التي اختاروها هم أنفسهم بصفة شخصية (1).

لقد بثت الرواقية مبادئها السمحة في القانون الروماني، فجعلت من ذلك القانون الطبيعي والقانون الفلسفي كما يتصوره العقل قانونا للإنسانية، يمكن أن تتخذه جميع الشعوب

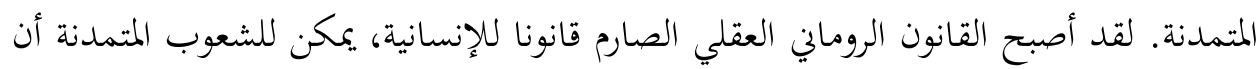
تتخذه قانونا عاما، وذلك بفضل المبادئ السمحة التي دخلت على هذا القانون. وخير مثال على ذلك هو بجموعة القوانين المعروفة باسم Institutes والتي تم تدبيجها بأمر الإمبراطور جستنيان في عام "533 بعد الميلاد"، متخذة من مبادئ الرواقيين مرشدا ومستخدمة منهجهم في صياغة عبارات مبادئ قانون الطبيعة ius naturae وقانون الأمم (العشائر) ${ }^{(2)}$ ius gentium يتكرر تأثير الرواقية عند شيشرون غير مرة في تعريفه للقانون، وكأن الفلسفة الرواقية كانت المبدأ الخاص بقانون الطبيعة الذي جعله الرومان قانونا مبسطا مرتبا، وعليه يبدو أنه من تروتيك المؤكد أن الرواقيين هم الذين دعوا المشرعين إلى اعتبار العقل وطبيعة الأشياء أساسا سليما للتشريع الخاص بالحقوق (3). وهناك من يقول أن الفلسفة الرواقية حينما انتقلت من مدرسة زينون إلى روما وجهت عنايتها إلى الفرد وإلى المدينة، ومضت في شعورها بالاحترام لطبيعة الكائن العاقل والإجلال لحقوق المواطن، فكان من ثمراها كتب كالجمهورية والقوانين لشيشرون التي قرر مبدأ الانسجام بين الإله والإنسان وأن الجماعة أساس لوحدة الجنس البشري ومبدأ للجماعات البشرية(4).

$$
\text { 1- } 1 \text { - عثمان أمين، المرجع السابق ص177. } 179 \text { - 180. }
$$

3- Renan, F., Marc-Aurele et la fin du monde antique, 1882, p.p. 22-23.

4- La ferriere, I. F., " Mémoire concernant l' influence du Stoïcisme sur la doctrine des jurisconsultes romains" dans Mémoires de l' Académie des Sciences Morales et Politiques, t. x., Paris, 1860, p. 579. 
وهناك من يقول أن المبدأ الذي يذهب إلى أن على الدولة إزاء أفرادها واجبات كواجبات الآباء بحاه الأبناء هو مبدأ أعلن لأول مرة على رؤوس الأشهاد في عهد الإمبراطور والفيلسوف الرواقي ماركوس أوريليوس (1). يبدو أن قواعد التشريع الروماني إن لم تكن مشتقة من فلسفة رواقية فهي على الأقل

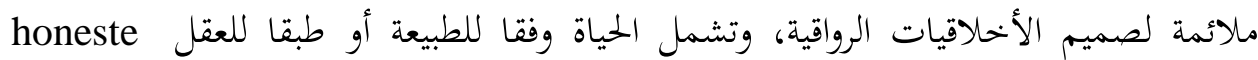
vivere الإنسان الفردي وقد اعتبرت أساسا للحق نفسه الذي يصبح قانون الإنسان في الجماعة، كما تتضمن هذه القواعد مبدأ عدم الإضرار بالآخرين alterum non laedere ويركز هذا المبدأ على علاقة الناس بعضهم ببعض حيث تنص على ألا يؤذي أحد غيره، أي أها تنص على وجوب احترام الإنسان لأخيه الإنسان، وعدم الاعتداء على شخصه الذي يشمل حريته وسمعته وحياته، وأخيرا يأتي مبدأ إعطاء كل ذي حق حقه suum cuisque tribuere ضرورة رد الحقوق إلى أهلها مما يعني احترام الملكية واحترام قواعد الالتزام وواجبات العدالة قبل جميع الناس بحسب استحقاق كل واحد أو عدم استحقاقه (2). ويرجع الفضل في الإصلاحات التي أدخلت الإنسانية على القانون القديم وخفضت من حدته، كما أدخلت القانون الروماني إلى عصره الفلسفي إلى اثنين من الأباطرة ألا وهما الإمبراطور أنطونينوس والإمبراطور ماركوس أوريليوس، الفيلسوف الروماني الذي تأثر هو الآخر التره بالفلسفة الرواقية مثل بقية المشرعين الرومانيين في القرن الثاني الميلادي الإنئ. وكان في مزج الرواقية بالتشريع انتصار للروح اليونانية على الروح اللاتينية، وإيثار لفكرة الإنصاف على صرامة القانون وتغليب لأساليب اللين على أساليب العنف والشدة، وبمع بين

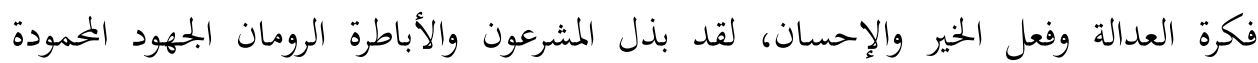

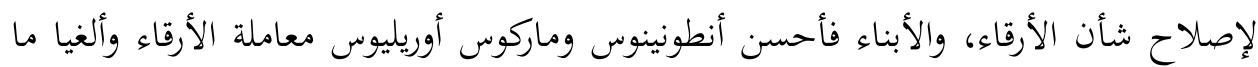

1- Renan, F., Op. cit. , p. 20.

2- Iustinianus, Digesta Iustiniani, Book 1, ch. 1, par 10, Sec. 2.1.1. 3- عثمان أمين، المرجع السابق ص181-182. 
كان في نظام الرق من شناعات، فأصبح للرقيق شخصية أخلاقية وأصبح العبد عضوا من أعضاء المدينة وأصبح قتله جريمة تستحق العقاب (1). وقد نظمت العقوبات البدنية، وأصبح النظر في قضايا الرقيق من اختصاص المحاكم، وكذلك سنت تشريعات أخرى تغلب عليها المسحة الإنسانية ويقبلها العقل السليم وكان من تلك القوانين ما يتصل بتنظيم حال الابن والزوجة والقاصر، فحد التشريع الجديد من حرية الأب في استعمال القسوة مع الأبناء ولم يعد الابن مملوكا لأبيه أو شيئا من أشيائه كما كان الحال من قبل (2).

ولقد كان القانون القديم يعتبر الأم جزءا من أسرة زوجها وأولادها، فأصلح ماركوس أوريليوس من هذا النقص، ونص في التشريع الجديد على حق الأم في إرث ابنها وحق الابن في إرث أمه، وأصلحت العيوب التي كانت في القوانين الخاصة بالوصاية والتوكيل (3). ويظهر أن النظرية الرواقية في القانون الشائع أو الناموس العام كانت Koovòs vònò من البواعث التي حملت الرومان على أن يعدلوا نظام الحقوق عندهم، فيبثوا فيه مبدأ الإنصاف ويبعدوا عنه كل ما كان من قبيل العادة الآلية أو امتياز طبقة من الناس على غيرهم (4). وقد بث كبار رجال القانون الذين تلقوا الكثير من تعاليم المدارس الرواقية هذا المبدأ في التشريع الروماني، وعلى ذلك فإن الفلسفة الرواقية قد تركت في التشريع الروماني آثارا بعيدة المدى، وصبغته صبغة عقلية أخلاقية فضمنت البقاء والدوام حتى أصبح مع شيء من التحوير والتعديل، قانون الشعوب الحديثة المتحضرة(5).

1- Renan, F., Ibid, pp. 22-24.

$$
\text { 2- 2 - عثمان أمين ، المرجع السابق، ص182. }
$$

3- Iustinianus, Digesta Iustiniani, book 3, and 4.

4- Vernon, Arnold, Roman Stoicism, New York, 1958, P. 385.

$$
\text { 5- عثمان أمين، المرجع السابق، ص ص183-184. }
$$




\section{نماذج من فلسفة ماركوس أوريليوس:}

كانت أخلاق الرواق عماد العقائد والفضائل الجمهورية في نفوس الكثيرين، وفي عهد

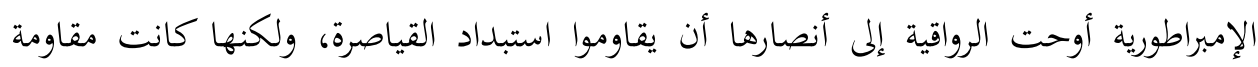

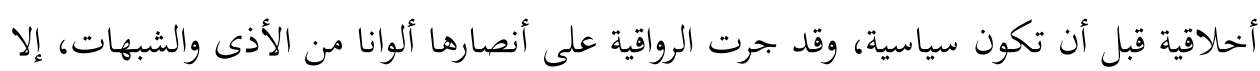

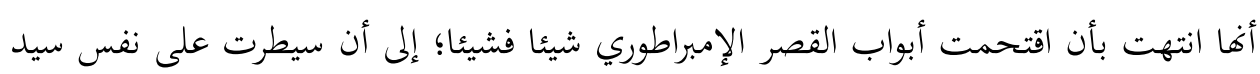

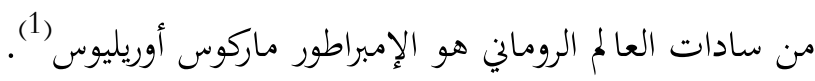

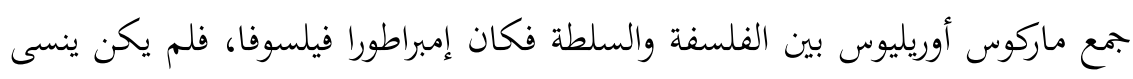
واجبات الإمبراطور كما لم تفارقه لحظة شيمة الفيلسوف؛ ولقد آثر ماركوس أوريليوس الفلسفة على الخطابة واختار المذهب الرواقي فاعتنقه بصدق وإخلاص، لكن موقف الإمبراطور ماركوس أوريليوس من الرواقية كان موقف القاضي ولم يمثل المدافع عنها، حيث قدم الشكر للإله الذي أعانه على إغفال المنطق والطبيعيات وعدم الأخذ بمسلمات الأمور (2). وبهذا استطاع هذا الإمبراطور أن يبرر بعض خصائص تلك الفلسفة وقد مست هذه الخصائص قلوب الناس في زمانه والتي أصبحت بهذه المثابة آخر رسالة بعث بها العالم القديم إلى الأجيال المقبلة، ولم يكن في رواقيته متشددا ولا جافيا بل كان في مذهبه لين ويسر وإنسانية وهي خصائص لم تعرفها الرواقية القديمة، وكان يتحاشى ذكر الاصطلاحات الرواقية البحتة فكان قوله أيسر على السمع وفكره أحرى إلى القلوب، ولقد تخلى عن بعض العقائد الرواقية التي لم تكن توافق الإنسانية؛ فقد كان يرى أن ارتكاب الخطيئة ابتغاء اللذة أشد من ارتكاها لدفع آلم أو

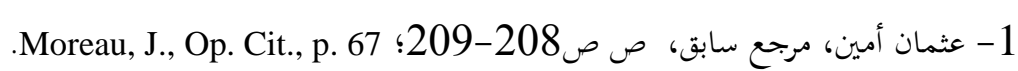
2- Marcus Aurelius, book 1, chapter 17, section 9, line 3 to 5:

( ( كما تستخدمه كما رغبت في الفلسفة فإنني لم أقع في أيدي سفسطائي ما، ولم أجلس إلى منضدة المؤلفين،

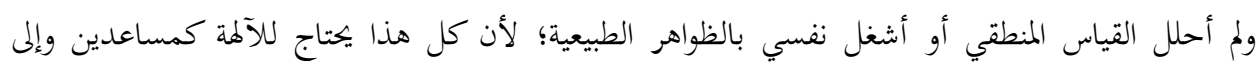
.)(الحظ) 
دفع مضرة، ولا بحد في حكمة ماركوس أوريليوس من الثقة والاعتزاز بالنفس ما تستشعره في أقوال الأقدمين وأعمالهم (1). لم يؤيد ماركوس أوريليوس إمكان المعرفة اليقينية بل أيد اعتراض المعترضين على الرواقية القديمة في هذا، حيث يؤكد؛ كأنما ألقى على الأشياء حجاب كثيف حتى بدا للكثير من الفلاسفة أن اليقين شيء لا يدرك ولا ينال، بل إن الرواقيين أنفسهم يحكمون بأن بلوغ ذلك الك

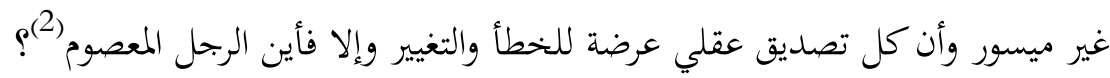

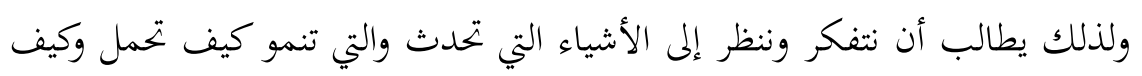
تختفي بسرعة، فالهوة لم تزل فارغة هنا على مقربة منا، واللا متناهي، سواء في الماضي أو في

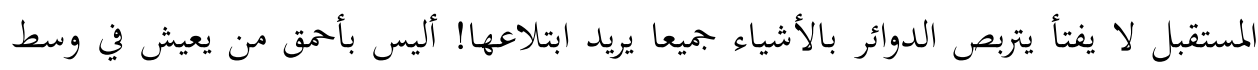

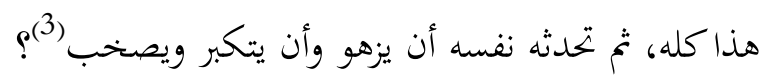
وحينما يتحدث ماركوس أوريليوس عن التغيير والفساد يصرح بأنه يجب على الفرد أن ينظر شذرا إلى تغيير وفساد كل شيء، ولأنه بناء على الطبيعة، لا يوجد شيء شرير لأنه طبق "موافق" للطبيعة (4).

ولهذا على الإنسان أن يدرك المعنى الضمني للأشياء والأفعال من السرقة إلى البذر والشراء والعيش، وذلك بنوع آخر من الرؤية غير البصرية، ويبدو أغها البصيرة(5).

$$
\text { 1 - عثمان أمين، مرجع سابق، ص } 210 .
$$

2- Marcus Aurelius, book 5, chapter 10, section 1, line 1-5:

( ( تكون الأشياء مثثل هذا النوع من التغليف كما تبدو للفلاسفة وليست للقليل منهم ولا الذين استتجوا أهم

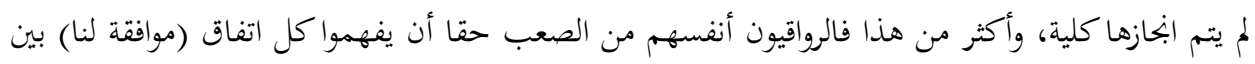

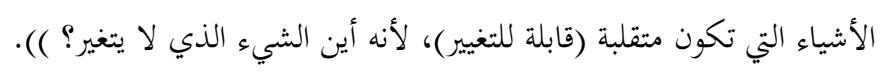

3- Marcus Aurelius, book 5, chapter 23, section 1, line 1 to chapter 24, section 1, line 1. 4- Marcus Aurelius, book 2, chapter 17, section 2, line 10-11.

5- Marcus Aurelius, book 3, chapter 15, section 1, line 1-3: 
فمن كلامه عن الإدراك الضمني بالنفس وتحكمها في نفسها، يمكن معرفة أنه لا يمكن للأشياء نفسها أن تتعلق بالنفس ولا تقترب من النفس ولا يمكن أن تحاول أن تحرك النفس، لكنها (النفس) هي فقط التي تحول وتحرك نفسها، وفيها تكمن الأحكام (القرارات) فإنها تعتبر

$$
\begin{aligned}
& \text { نفسها تستحق فعل هذا، مثلما تفعل لنفسها الأشياء التي ترتبط بهابـا. } \\
& \text { ويشير إلى أنه لم تكن الرذيلة منه فلماذا يعاني منها فيقول: }
\end{aligned}
$$

(( إذ لم تكن هذه الرذيلة مني أو نابتحة عن شر مني ولم يعان منها الاهتمام العام، فلماذا أهتم

كما "أتحمل هذا" وكيف يعاني منها الاهتمام العام؟ ()) (2).

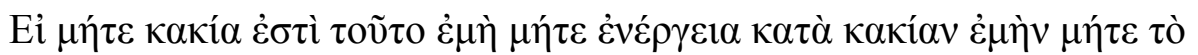

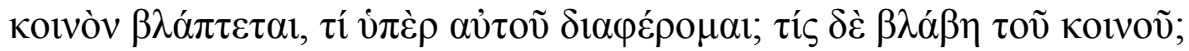

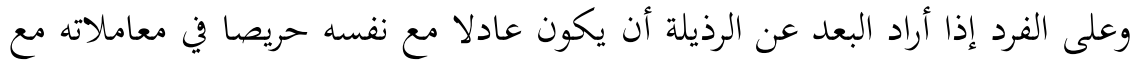

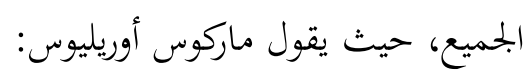

() كما قيل إن كل نفس سمعت أهما بحردة من العدالة والاعتدال وحب الخير ومن كل شيء مثل هذه الأنواع، هكذا فمن الضروري أن تتذكر كل هذا باستمرار لأنه سيجعلك أكثر لباقة

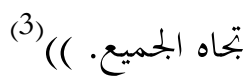

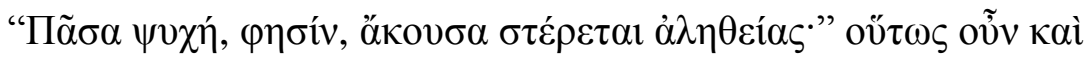

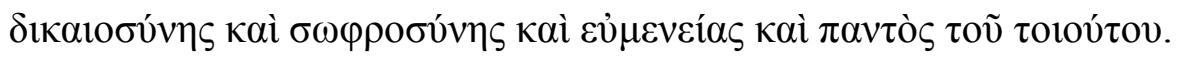

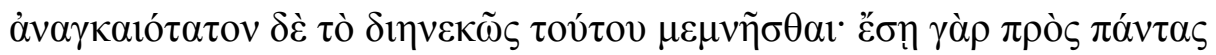
$\pi \rho \alpha \operatorname{có}_{\varepsilon} \rho \mathrm{o \zeta}$

وبناء عليه يتحدث إلى نفسه قائلا: (( يا نفسي، ألم تكوني عندئذ طيبة ويسيرة

ووحيدة وعارية، فلتكوني أكثر وضوحا من الجحد الذي يحيط بك؟ ألم تتذوقي حلاوة العاطفة؟

((لم يعرفوا المعنى الكامل للكلمات: أن يسرق، أن يبذر، أن يعيش في سلام، أن يرى ما يجب أن يفعل، فهذا

$$
\text { ليس بالعين ولكنه نوع أخر من الرؤية )). }
$$

1- Marcus Aurelius, book 5, chapter 19, section 1, line 1-4.

2- Marcus Aurelius, book 5, chapter 35, section 1, line 1-3.

3- Marcus Aurelius, book 7, chapter 63, section 1, line 1-4. 
ألم تكوني مكتظة بأي شيء أو في حاجة لأي شيء؟ فلا ترغبين في شيء أخر ولا تشتهين أي شيء إما حي أو جماد للتمتع بالمسرات؟ ()) (1). النظرية الدورية: - (n)

لقد بلغت النظرية الدورية قمتها في الفكر اليوناني عند الفلاسفة الرواقيين الذين اعتبروا

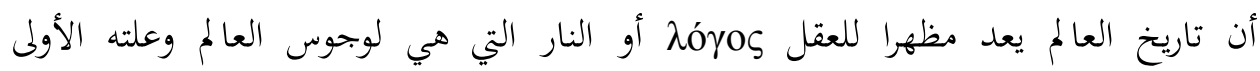
والوحيدة(2).

إن الارتباط بين نظرة الفيلسوف اليوناني إلى التاريخ وبين تفسيره للطبيعة جعل

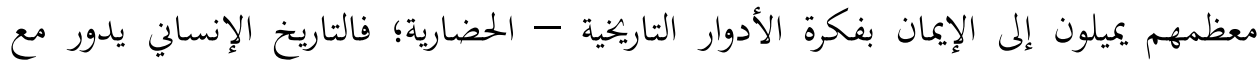

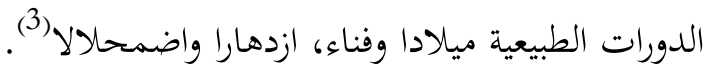

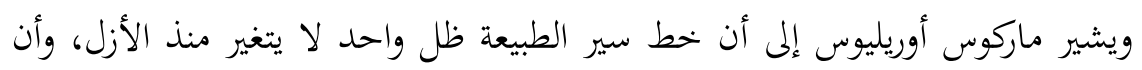
كل شيء يظهر في دائرة، وأن هذا العالم نفسه يعيش بالتغيرات المستمرة التي لا تلم بالعناصر فحسب، بل بتلك الأشياء التي تتكون من تلك العناصر في دورة مستديمة من تعاقب التوالد والتحلل بذكره المتواصل لعبارة وردت عند هيراكليطوس Heraclitus حيث يقول: (( فلتتذكر دائما قول هيراكليطوس إن الأرض تموت لتصبح ماء يموت ليصبح هواء وأن الهواء يموت ليصبح

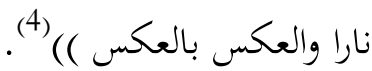
فالتاريخ كالنهر تتدافع أحداثه كتيار جارف لأنه بمجرد أن ترى شيئا قد حدث يحمله تيار الزمن بعيدا ويحل الآخر محله وهو سيحمله بعيدا أيضا، كما يرى ماركوس أوريليوس أن لا ثبات لشيء على وجه البسيطة وأن التغيير والتبدل قانون هذا العالم، وهو يشبه الطبيعة بسيل

1- Marcus Aurelius, book 10, chapter 1, section 1, line 1-5.

2- مصطفى النشار، من التاريخ إلى فلسفة التاريخ "قراءة في الفكر التاريخي عند اليونان، القاهرة، 1997م،

3- مصطفى النشار، المرجع السابق، ص82.

4- Marcus Aurelius, book 4, chapter 46, section 1, line 1-3. 
جارف لا تكاد الأشياء تظهر وتستقر هنيهة حتى يغمرها فإذا بها قد اختفت في طرفة عين، وكل شيء يحدث بطريقة متكررة، وعلى الفرد ألا يفعل أي شيء بدون غاية منه ويجب أن يتوافق هذا الشيء مع المبادئ الصحيحة في الحياة، والحقيقة أن الفاعلية الفردية في التاريخ لا يكاد يكون لها أي دور حقيقي في التاريخ إلا إذا توافق هذا الدور مع ما ترسمه العناية الإلهية للفرد من دور محدد).1)

ويضرب المثل بنفسه حيث يؤكد أنه يتوافق مع كل شيء وأن كل شيء قد انسجم

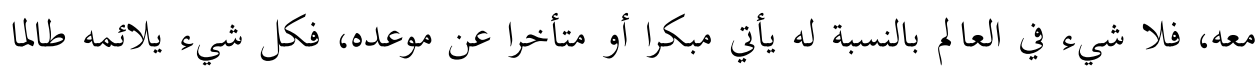

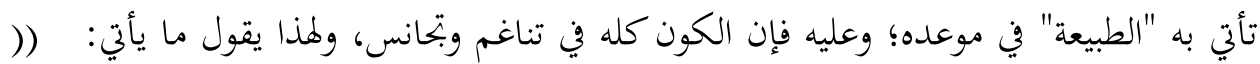

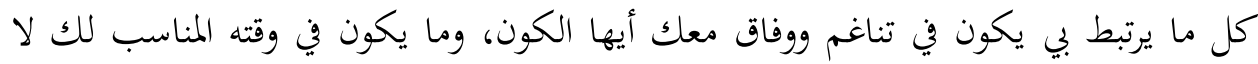
يكون مبكرا جدا ولا متأخرا جدا بالنسبة لي، كل ما تحمله الفصول لكول أيتها الطبيعة، يكون ثمرة لي، ومنك يكون كل شيء وفيك كل شيء وإليك يعود كل شيء )( ) (2). وبالنسبة للأسباب النهائية لأحداث التاريخ، يسلم بثلاثة أسباب محتملة وهي: 1. كل شيء وليد الصدفة المخضة. 2. كل شيء تحدده ضرورة محتومة.

3. كل شيء باستثناء ما يعود إلى حرية الإنسان يرتكن إلى عناية شفوقة ورحيمة حسنة)

لقد اقتنع ماركوس أوريليوس بالنظرية التي تقول إن جميع الأشياء في النهاية واحدة، وإن الإنسان يعيش لا في فوضى وعماء، بل في عالم مرتب منظم، فيذكر أن الأشياء كلها متسلسلة

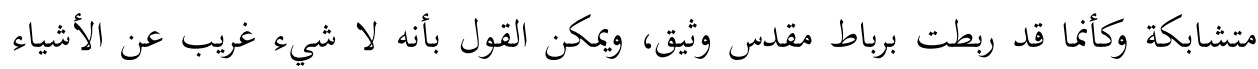

1- Marcus Aurelius, book 4, chapter 43, section 1, line 1 to book 4, chapter 44, section 1, line 2.

2- Marcus Aurelius, book 4, chapter 23, section 1, line 1 to line 3.

3- ألبان ويدجري، التاريخ وكيف يفسرونه من كنفوشيوس إلى توينب، ترجمة: عبد العزيز توفيق جاويد، الهيئة

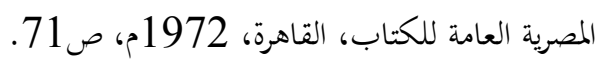


الأخرى؛ لأنها جميعا قد رتبت معا، وهي تتعاون على تحقيق ما في العالم الواحد من حسن النظام، وذلك أن العالم المؤلف من جميع الأشياء واحد، والإله الملازم في كل مكان والمسيطر على الجميع واحد، والمادة والكون واحد، والقانون واحد، والعقل الشائع في جميع الموجودات

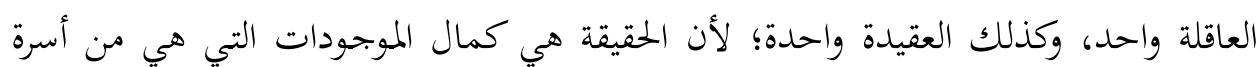
واحدة والتي منحت عقلا واحدا(1).

إن الحرية الحقيقية للحكيم الرواقي تكمن في أن تتوافق أفعاله مع الغايات النهائية للعالم، فهو يحتفظ بحريته إزاء ذلك القدر المحتوم إذا ما اختاره اختيارا، وحينما يدرك أنه قدره: فالعقل والتفكير العقلي الفلسفي على حد قول ماركوس أوريليوس هي قوى الإنسان التي تكفي

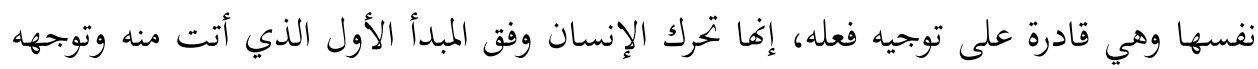
نهو تحقيق الهدف الذي حدد له من قبل، فتكون النتيجة المترتبة على ذلك أن كل الأفعال يمكن

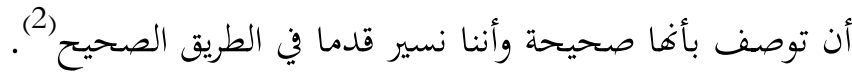
ماركوس أوريليوس ومواقفه الدينية والدنيوية:

وبالاعتقاد بالقدر المحتوم اطمأن ماركوس أوريليوس إلى العناية الإلهية وذلك من

الناحيتين النظرية والعملية: فمن الناحية النظرية فإن نظرية التقاء الذرات بالصدفة لا تنسجم مع الاعتقاد بالوحدة القصوى للوجود، ومن الناحية العملية لأن الإنسان يجد في الاعتقاد بالعناية نقطة يبدأ منها عمله ونشاطه في هذه الدنيا، إذ يهم الإنسان أن يختار بين أمرين: فإما أن يكون السلطان للصدفة والحظ وإما أن يكون للعقل والتدبير، فيطلب أن لا نسخط على ما قسم لنا من نصيب في الكون وأن نتذكر أننا مضطرون إلى أن نختار، فإما أن يكون هناك عناية مدبرة وإما ذرات عمياء (3).

1- Marcus Aurelius, book 7, chapter 9, section 1, line 1 to book 7, chapter 12, section 1 , line 1.

2- Marcus Aurelius, book 5, chapter 14, section 1, line 1 to line 4.

3- Marcus Aurelius, book 4, chapter 3, section 2, line 7 to line 9. 
ويشير إلى أن الكون إما فوضى واختلاط وتشتت، وإما وحدة ونظام وعناية، وإذا

كانت الفوضى فإن ماركوس أوريليوس لا يرغب في الوجود بين هذا الحشد المدفوع إلى الصدفة والاختلاط، ولماذا يعتني بشيء آخر غير تحول التراب إلى التراب؟ ولماذا يصيب نفسه بالاضطراب؟ فإن الإنسان سوف يموت ويتحول إلى التراب الذي جاء منه، وإذا كانت الوحدة والنظام والعناية، فإنه سيقف ثابتا لا يتزعزع، متوكلا على من بيده تصريف الأمور (1). فكثيرا ما يلجأ الإمبراطور إلى البراهين الرواقية لإثبات وجود الإله الواحد، ولكن سرعان ما ييدو أن استمساكه بالدين المقرر لم يكن قائما على حجج فلسفية، ويتجلى في بحثه لمذه المسألة شيء من الحماسة وحرارة العقيدة، إذا صح أن الآلمة لا تمتم بشيء ولا تفكر في شيء، ومثل هذا الاعتقاد زيغ وضلال: فلتترك إذن الأضاحي والصلوات والنذور والشعائر الأخرى التي نتمثل بها في أذهاننا حضور الآلهة وقربها من حياتنام2.

ويرد ماركوس أوريليوس على من يتساءل عن وجود الآلةة، بأن الإنسان لم ير نفسه مع

أنه يبجلها ويحترمها، وكذلك فإن الآلهة إذا كنا لا نراهم رغم أفم غير مرئيين للعيون فإننا نبجلهم ويقول في ذلك تحديدا: (( إلى أولئك الذين يسألون: أين رأيت الآلهة أو كيف تفهم أهم موجودون حتى تعبدهم؟ في المقام الأول إهم لم يكونوا مرئين للعين، في المقام الثاني فإنني لا أرى أبدا روحي ولكني أبجلها، عندئذ لذلك بخصوص الآلهة مما جربته من قدرقم الدائمة من

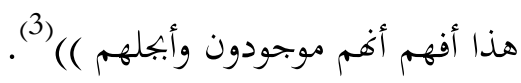
إن النفس عند ماركوس أوريليوس هي الدليل على وجود الآلة؛؛ فإن الإنسان إذا أراد التأمل فعليه ألا يذهب إلى الريف والبحر وإنما فقط يخلو إلى نفسه فهي معين لا ينضب بل

1- Marcus Aurelius, book 6, chapter 10, section 1, line 1 to line 6.

2- Marcus Aurelius, book 6, chapter 44, section 2, line 2 to line 9.

3- Marcus Aurelius, book 12, chapter 28, section 1, line 1 to line 6 . 
يزداد حكمة وعمقا بهذا التأمل، حيث يذكر: (( لأنه ليس هناك مكان أكثر سلما وخال من

$$
\text { المموم يمكن لإِنسان أن يلجأ إليه أكثر من نفسه )(1). }
$$

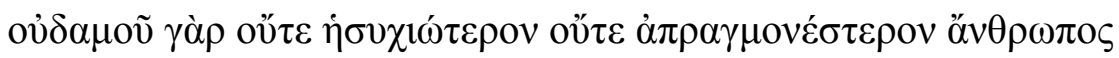

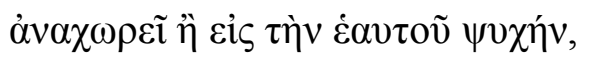

ويستمر في قول: (( والأكثر من هذا بقدر ما يمتلك هذا بداخله، فإن نظرة ثابتة إليه

ففي الحال يصبح في راحة كاملة، لا أعني بالراحة الكاملة شيئا أكثر من الترتيب الجيد، لذذلك

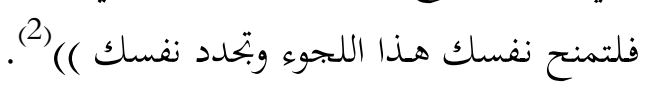

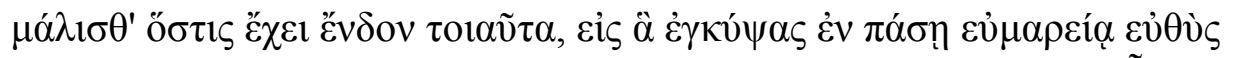

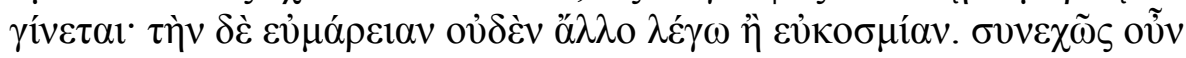

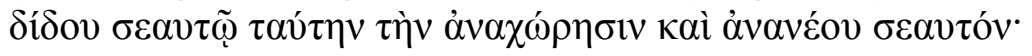

ويبدو للوهلة الأولى أن ماركوس أوريليوس يدعو إلى الانصراف عن شئون الحياة، ولكن

ذلك ليس صحيحا، حيث يدعو ماركوس أوريليوس إلى الترتيب الدقيق لما يجب على الإنسان

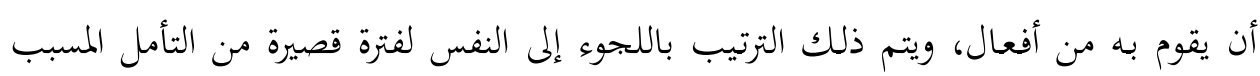
للراحة والهدوء (3)

\section{أخلاقيات ماركوس أوريليوس:}

لم يكلف ماركوس أوريليوس نفسه مشقة الإدلاء بنظرية مفصلة عن الفضائل والرذائل

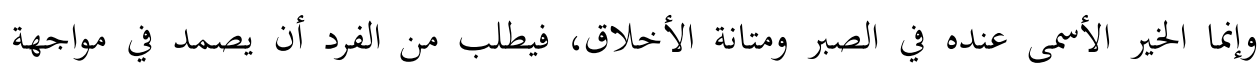
المشاكل التي تقف في مواجهة أمواج البحر بثبات(4).

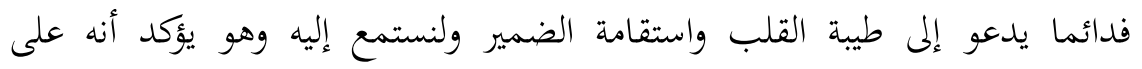

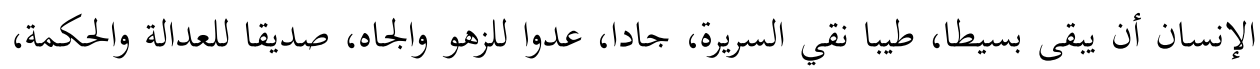

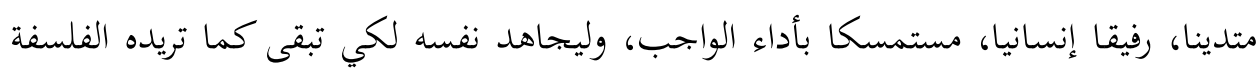
أن يكون، وليسبح الإله، وليكن دائما في عون الناس، فالحياة قصيرة، وثمرة وجود هذا الإنسان

1- Marcus Aurelius, book 4, chapter 3, section 1, line 4- 5 .

2- Marcus Aurelius, book 4, chapter 3, section 1, line 5- 8.

3- 3ثمان أمين، مرجع سابق، ص214.

4- Marcus Aurelius, book 4, chapter 49, section 1, line 1 to section 2, line 3. 
على الأرض أن يصون نفسه مطهرة، وأن يفعل ما يعود بالخير على الجماعة، فيقول في هذا:

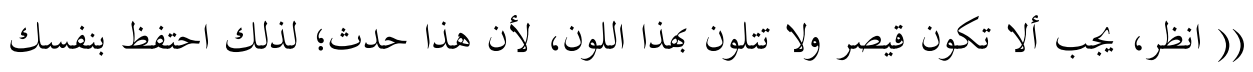
رجلا بسيطا، طيبا نقي السريرة، جادا، صديق العدالة ومتدينا وكريما وعاطفيا ونشيطا في أداء الأعمال المناسبة، فلتجاهد لكي تستمر لتكون مثلما رغبت الفلسفة أن بتعلك، فلتسبح الآلمة وتنقذ البشر، فالحياة قصيرة وثمة ثمرة واحدة لهذا الوجود الأرضي، هي النزعة الدينية والأعمال الاجتماعية () (1) (1)

ويمضي في تسامحه وكرمه نازعا دائما إلى فعل الخير لأجل الخير، ومن غير أن ينتظر من

الناس اعترافا بالجميل، وهو يريد أن يكون في فعله على حد تعبيره الجميل: (( كشجرة الكرم

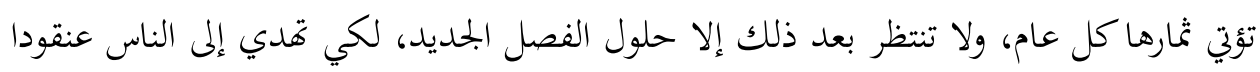
جديدا () (2) (2)

ويؤكد أن غاية النفس هي تأدية العمل الذي خلقت له، والإنسان إنما خلق

بطبيعته عاقلا، فحسبه إذن لكي يصيب خيره ويبلغ غايته أن يحيا وفقا لطبيعته، يعني وفقا

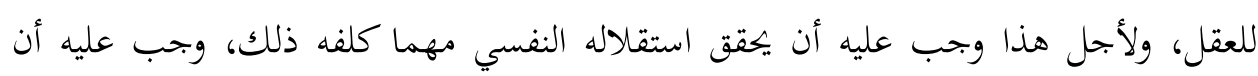
يصون ذلك الاستقلال، سواء أكان بإزاء غيره من الناس أم بإزاء القيل والقال، أم بإزاء الآراء

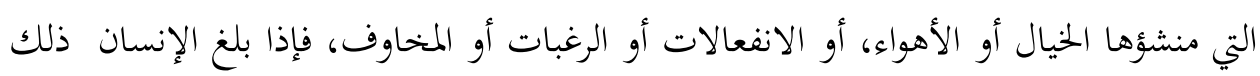

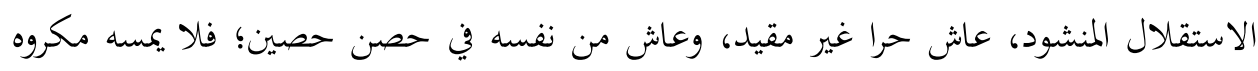
ولا يستطيع أحد أن يلحق به ضرا، ولو كان الإنسان لا ينخدع بظواهر الأمور لاتبع سبيل

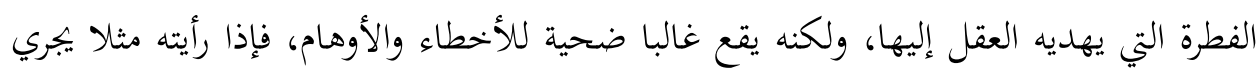

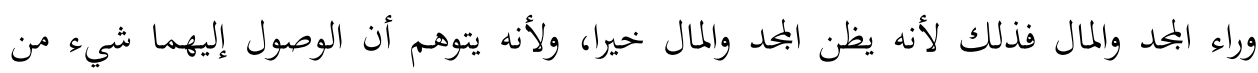

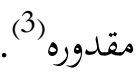

1- Marcus Aurelius, book 6, chapter 30, section 1, line 1 to section 3 , line 3 . 2- Marcus Aurelius, book 5, chapter 6, section 1, line 5 to section 2, line 9.

3- عثمان أمين، مرجع سابق، ص ص215-216. 
وهنا يظهر إصرار ماركوس أوريليوس والرواقيين على التفرقة بين الأشياء التي في قدرتنا، والأشياء التي ليست في قدرتنا: فكل ما هو أجنبي وخحارج عنا ليس في مقدرتنا، والذي في مقدورنا هو ملكات نفوسنا، وعلى الخصوص قدرتنا النفسية على أن نصدق الأفكار التي نحكم ببداهتها، وقدرتنا على الرفض والتوقف عن الحكم، فكل شيء إنما هو رأي من الآراء، وفي مقدورنا أن نرى في الأشياء الرأي الذي نريده، ويؤكد على احترام ملكة الرأي: فكل شيء

$$
\text { راجع إليها، وهي كل شيء في الإنسان(1). }
$$

ونظرا للقول بمحدودية قدرة الإنسان وذلك لكثرة الصعاب التي تواجهه، فإن الحكيم لا

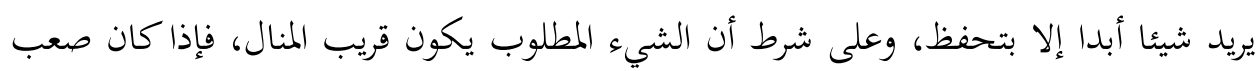
المنال، فالرجل الذي يكون قد تحفظ في طلبه لا يشعر من جراء فشله في بلوغه بأي ألم أو خيبة

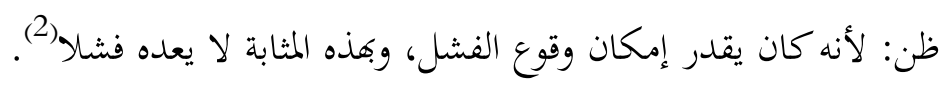
ويشير إلى أن الشخصية المتكاملة هي التي تقضي يومها كما لو كان اليوم الأخير لها فيقول: () يتكون كمال الشخصية الأخلاقية من قضاء كل يوم كما لو كان هو الخير "آخر

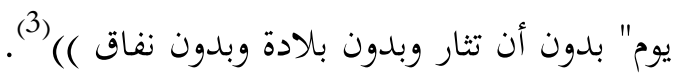

كل هذه دروس لتهذيب النفس فيضيف إن أفضل الطرق للانتقام من النفس ألا نفعل

$$
\text { مثل هذا الشيء (4). }
$$

’A

وإن الفرد يعاني من هذه الأشياء بعدالة ويختار أن يصبح جيدا غدا أكثر من أن يكون

جيدا اليوم، ويتحدث عن الثروة أن يمتلكها الفرد بلا غطرسة وأن يتخلص منها بسهولة(5).

1- Marcus Aurelius, book 3, chapter 9, section 1, line 1 to line 4.

$$
\text { 2- 2- عثمان أمين، مرجع سابق، ص216. }
$$

3- Marcus Aurelius, book 7, chapter 69, section 1, line 1 to line 2 .

4- Marcus Aurelius, book 6, chapter 6, section 1, line 1.

5- Marcus Aurelius, book 8, chapter 22, section 1, line 1 to line 4 . 
يطالب الفرد بأن لا يتكاسل ولا يحار في الحديث ولا يكون غامض الفكر فيقول: () لا تفعل هذا بكسل ولا تتحير في الحديث ولا تكن غامضا في أفكارك "ولا تضل" ولا تدع روحك مركزة كلية في نفسها ولا تثار ولا تشغل نفسك بوقت الفراغ في حياتك )) (1).

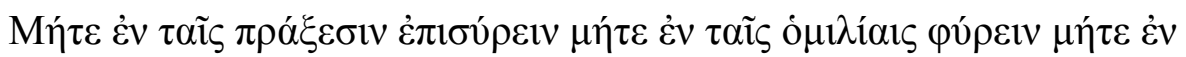

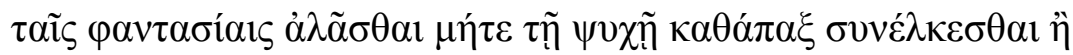

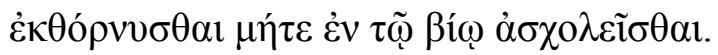

نظرته للحياة والتأهب للموت:

يظهر من ثنايا كتابه آثار الانقباض والعبوس، فلقد تعلم من إبيكتيتوس مبادئ الاستسلام والإذعان، ولكنه لم ينظر إلى العالم نظرة الفرح والابتهاج تلك النظرة التي بتعل الحكيم يشعر بأنه ملك ولو كان عبدا، لكن من خواطره يظهر انه يشعر بعبوديته وأنه من رعايا

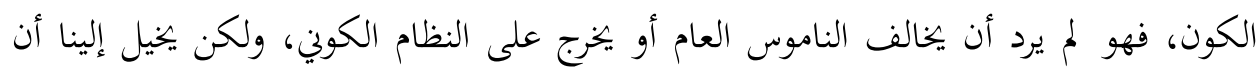

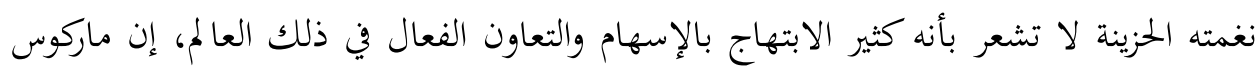
أوريليوس يمثل الرواقية حين صبغها اضمحلال روما بلون قاتم (2).

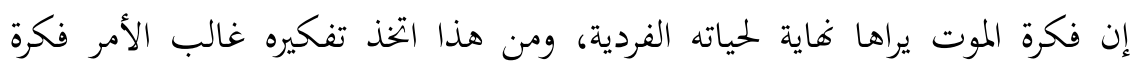
الموت مبدأ هاديا في الأخلاق، ولذلك كانت أخر رسالة له شبيهة برسالة الفيلسوف العبد إبيكتيتوس في قوله: "اصبر وتزهد" حيث يقول إبيكتيتوس: (( إنني أمارس الصبر والتزهد والتعاون () (3)

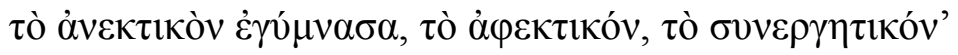
حيث يقول: (( فلتقل لنفسك في الصباح، إني سألتقي بالجسد المشغول، عديم العرفان بالجميل، القاسي، المخادع، الحسود وغير الاجتماعي، تحدث كل هذه الأشياء لهم

1- Marcus Aurelius, book 8, chapter 51, section 1, line 1 to line 3.

2- Vernon, Arnold, Op. Cit., , P. 125.

3- Epictetus, Dissertationes ab Arriano digestae, book 4, chapter 4, section 18, line 5

LOEB Classical Library, Trans. by W. A. Oldfather, 1989. 
بسبب جهلهم بما هو جيد وشرير، لكنني رأيت طبيعة ما هو جيد أنه جميل وطبيعة ما هو شرير أنه قبيح، وطبيعة من يخطئ أنه شبيه بي، ليس بالدم ولا بالنسل ولكن بذكاء ونصيب من الإله، إنني لم أستطع أن أصاب بأي منهم لأنه لا يوجد شخص يمكنه أن يلقي بي في هذا الخجل، ولا يمكنني أن أغضب من قريبي أو أكرهه، لأننا خلقنا للتعاون مثل الأقدام ومثل الأيدي والجففون ومثل صفوف الأسنان العلوية والسفلية، ولذلك فإن اعتراض كل منا الآخر يكون ضد الطبيعة، ويظهر الاعتراض فيما بينا بالغضب والاشمئزاز ()). ويقول أيضا: (( تذكر كم أخرت هذه الأشياء وكم مرة تلقيت الفرصة من الآلهة ولم تستخدمها في الموعد المحدد ولكن الآن، إذ لم يكن من قبل، يجب أن تدرك أنك جزء من الكون وكانثاق من المسيطر على الكون فإنك تستمر، وأن هذا التحديد للزمن قد وضع لك، إذ لم تستخدمه لإزالة الغيوم عن عقلك فإنه يذهب وستعود أنت، ولن يعود )(2). فيطلب ماركوس أوريليوس من الإنسان عدم تحقير الموت لأن الموت جزء من الأشياء التي تطلبها الطبيعة، حيث يذكر: (( لا تحتقر الموت ولكن رحب به لأنه يكون جزءا واحدا من

$$
\text { الأشياء التي تريدها الطبيعة ()(3). }
$$

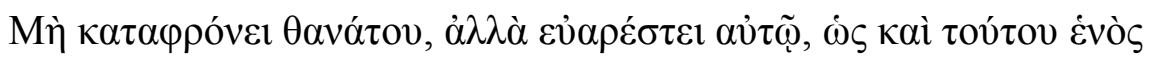

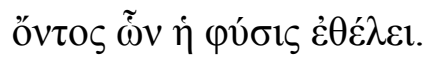

فمن يتفكر، لا يجزعه الموت ولا يخافه ولا يزدريه، بل ينتظره، كما ينتظر أمرا من الأمور الطبيعية، فيقول: (( لذلك فالرجل الذي يتفكر في هذا ليس بفظاظة ولا بتهور ولا بتكبر بتحاه

$$
\text { الموت، لكن فلينتظره كواحد من الأعمال الطبيعية )( (4). }
$$

1- Marcus Aurelius, book 2, chapter 1, section 1, line 1 to line 12.

2- Marcus Aurelius, book 2, chapter 4, section 1, line 1 to line 5.

3- Marcus Aurelius, book 9, chapter 3, section 1, line 1-2.

4- Marcus Aurelius, book 9, chapter 3, section 1, line 6-9. 


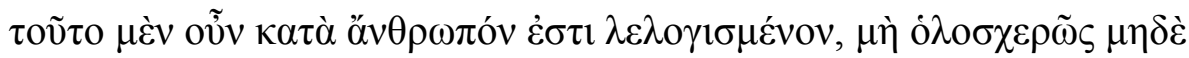

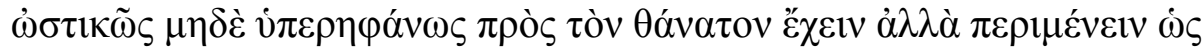

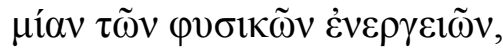

ويستمر أيضا في وصف التأهب للموت وأن النفس الجميلة هي التي تكون مستعدة

إذا اقتضى الحال أن تفارق البدن لساعتها لكي تفنى أو تتناثر أو تبقى بعد البدن، ولكن ليكن ذلك الاستعداد ثمرة لاعتقاد، واقتناع، لا لمجرد الرغبة في المعارضة ومخالفة المألوف، كما يشاهد عند المسيحيين وليكن استعدادا متعقلا، جادا، صادقا، طبيعيا، خاليا من الوقفات المصنوعة لته

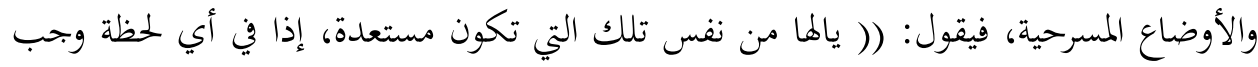

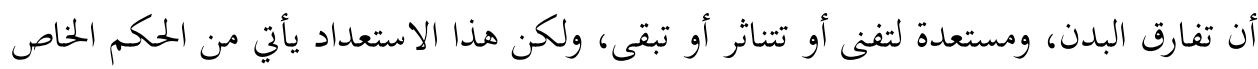

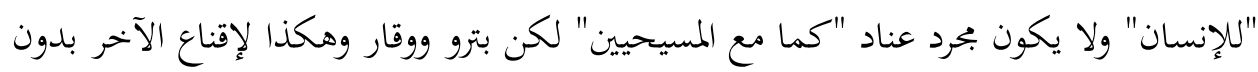
أداء عرض مسرحي ())

ويجب على الإنسان أن ينتظر باطمئنان إما أن يموت، أو أن تنتقل نفسه إلى مكان الآلهة

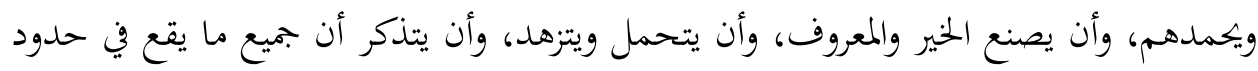
الجسم والحياة ليس ملكا له، ولا هو في مقدوره و(2). ويتحدث عن الموت مرة أخرى فيقول: (( يجب عليك أن تتوقف مرارا في كل شيء تفعله، لتسأل نفسك، إذا كان الموت مخيفا بسبب التجرد من هذا الشيء؟ () (3).

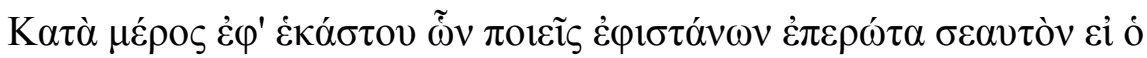

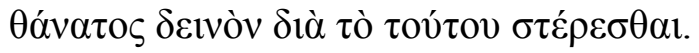

ويتحدث عن الموت بأنه قدر الإنسان ولا يمكن الهروب منه حيث يقول: (( لا تعتقد كما لو كنت ستحيا عشرة آلاف سنة ، إن الموت يتعلق بك بينما تحيا، وبينما يكون في قدرتك أن تكون جيدا () (4)

1- Marcus Aurelius, Book 11, chapter 3, section 1, line 1-5.

2- Marcus Aurelius, Book 5, chapter 33, section 1, line 1-5.

3- Marcus Aurelius, Book 10, chapter 29, section 1, line 1-2.

4- Marcus Aurelius, Book 4, chapter 17, section 1, line 1-2. 


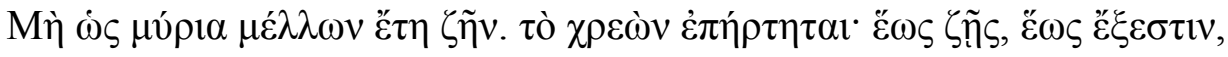

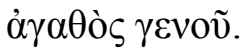

\section{المساواة بين الناس:}

يبدو من خلال كتابات ماركوس أوريليوس أنه يدعو إلى المساواة بين الناس، فهم جميعا متساوون، وهم من العقل أنصبة متساوية، وهم من أجل هذا يحبون الاجتماع؛ ذلك أن الموجودات كلما ارتفعت في المنزلة زاد ائتلافها وابنذابها بعضها إلى بعض، فينبغي إذن على رلى الناس بحسب قانون الطبيعة أن يتحابوا وأن يتواصلوا ، وهم مندوبون، إلى أن يتعاونوا أوثق التعاون في سبيل العمل الشامل والخير العام (1).

ولقد أوصت الفلسفة الرواقية أن يعامل الناس بعضهم بعضا معاملة الإخوان، إذ الناس

على اختلاف ألوافم وشعوبهم بتمعهم وحدة العقل والجوهر، ولا ينسى ماركوس أوريليوس أن يلفت النظر إلى رابطة القربى التي تصل بين كل أفراد الناس وبين الجنس البشري عامة، ولا يعادل هذه القرابة، في نظره قرابة الدم ولا قرابة المولد: لأها قرابة قائمة على شرف الانتساب إلى عقل واحد

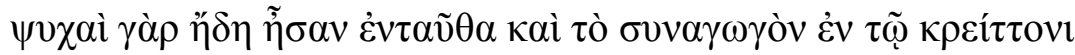

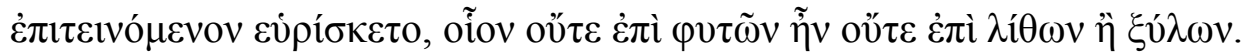

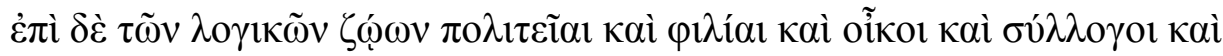

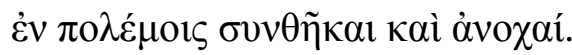

وإذن فواجب التعاون وحسن المعاملة يقتضي الوئام والاتحاد، ولربما امتاز الإنسان بأنه قد يحب حتى من اعتدى عليه فيقول في ذلك: (( فلتزين نفسك بالبساطة والتواضع وبالحياد تجاه الأشياء التي تقع بين الفضيلة والرذيلة، فلتحب الجنس البشري ولتتبع الإله )(3).

$$
\text { 1 - 1 عثمان أمين، مرجع سابق، ص218. }
$$

2- Marcus Aurelius, Book 9, chapter 9, section 2, line 3-6.

3- Marcus Aurelius, Book 7, chapter 31, section 1, line 1-2. 


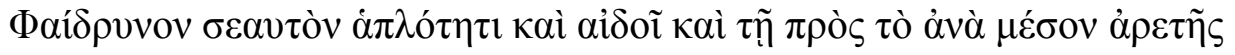

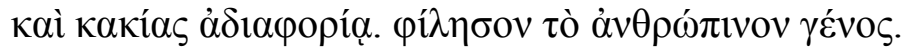

وعلى هذا فإن ماركوس أوريليوس يرى أنه إذا كان الناس يأتون الشر ويسيئون إلى

غيرهم، فذلك في الحقيقة، على الرغم منهم ولأفهم يخطئون؛ ولهذا يرى الفيلسوف الإمبراطور أنه إنه

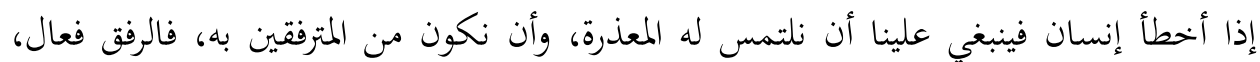
قوي الأثر في النفوس على شرط أن يكون بريئا لا يشوبه عبوس ولا نفاق... "فإذا أخطأ مخطئ فأقبل عليه، وتحدث إليه في رفق، من غير إعنات ولا لوم ولا ضغن ولا استهزاء، ولا تكلمه كما تكلم تلميذا في المدرسة، ولا لكي تشرئب أعناق الحاضرين إعجابا بك، بل تحدث إلى إليه وكأنه وحده من غير شهود، حيث يقول: (( يجب ألا تفعل هذا بنفاق ولا إهانة، ولكن بعطف وبدون ضغينة في قلبك، ولا كما لو أنك تعلمه ولا حتى لكي يعجب بك بك متفرج آخر، ولكن كما لو كان حقا بمفرده وحتى إذا حضر الآخرون ()) (1). الرضا بالمكتوب وتحمل المشاق:

يجث ماركوس أوريليوس الإنسان على الاجتهاد ليحيا سعيدا، فيقول له: إذا كان يجب إنبان

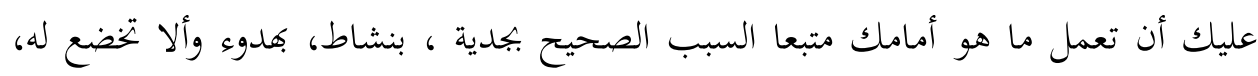
لكن حافظ على ما هو مقدس طاهر كما كان، ويجب عليك أن تكون مرتبطا أن تعيده في الحال، وإذا كنت متمسكا بهذا فعليك ألا تتوقع شيئا ولا ترب منه، ولكن أن تكون راضيا بنشاطك الحالي طبقا للطبيعة وبالحقيقة البطولية في كل كلمة وصوت تنطقه ستحيا سعيدا، ولا يوجد شخص قادر على منع هذا (2). ويحث الإنسان على الصبر على البلوى لأهما زائلة بسرعة، فيقول: (( فلتمح

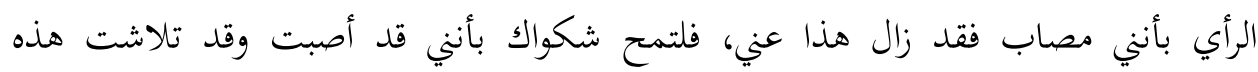
الإصابة () (3) (الراي باني

1- Marcus Aurelius, Book 11, Chapter 18, section 4, line 11 to line 14.

2- Marcus Aurelius, book 3, chapter 12, section 1, lines 1-6.

3- Marcus Aurelius, book 4, chapter 7, section 1, line 1-2. 


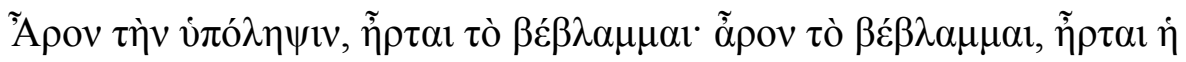
$\beta \lambda \alpha ́ \beta \eta$.

ويهفز الإنسان على الاستفادة من وقت الفراغ وعدم قضائه فيما لا ينفع وأن ينظر

الإنسان فيما يفعل جيدا، فيقول: ((كم هو عظيم وقت الفراغ الذي يستفيد منه من لا يرى ما قاله جاره أو فعله أو يقصده، ولكن فقط ما يفعله هو نفسه، حينما يكون هذا الشيء عادلا وتقيا "صحيحا"، حقا إنه ليس للرجل الصالح أن يتفكر في أن يتمعن في العادات ولكن من

$$
\text { يجري مباشرة لمدف وهو لا ينظر جانبا ()) (1). }
$$

ومن جهة أخرى يطالب ماركوس أوريليوس الفرد أن يتذكر ما قد يحدث له من أذى

في المستقبل فعليه أن يتحمله بشرف، فيقول: (( فلتتذكر في المستقبل ما يقودك إلى الغيظ "الإثم"، فلتستخدم هذا المبدأ، ليس هذا سوء حظ ولكن أن تتحمله بشرف يكون حظا جيدا () (2)

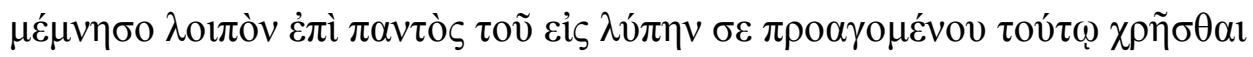

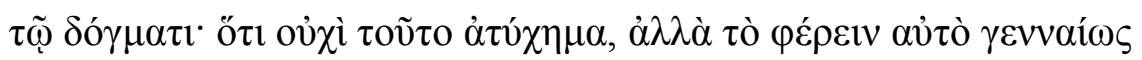

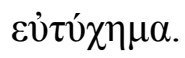

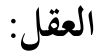

يبدو مما سبق أن كل ما يدعو إليه ماركوس أوريليوس من فضائل وتحمل للمشاق

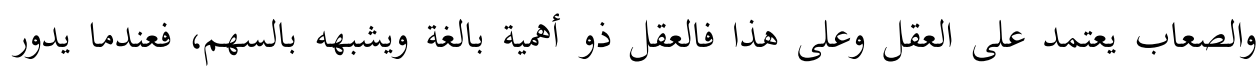
العقل حول التأمل فإنه يندفع للأمام مثل السهم، ويقول في ذلك: (( يتحرك السهم بطريقة وبطريقة أخرى يتحرك العقل، على الرغم من هذا عندما يتفحص العقل وعندما يدور في تأمل فإنه يتحرك مباشرة للأمام وليس للأقل في بتحاه هدفه ()) (3).

1- Marcus Aurelius, Book 4, chapter 18, section 1, lines 1-4.

2- Marcus Aurelius, book 4, chapter 49, section 2, line 5 to line 7.

3- Marcus Aurelius, book 8, chapter 60, section 1, line 1-3. 


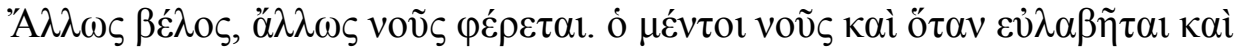

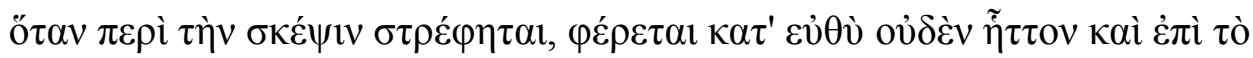
$\pi \rho о \kappa \varepsilon i ́ \mu \varepsilon v o v$.

تصبح الأشياء كلها مألوفة وبالخبرة التي يكتسبها من حياته، فيقول في ذلك: (( تكون

كل هذه الأشياء مألوفة وبالخبرة، يومية في حينها، وقذرة في موضوعها وكل شيء الآن كما كان في أيام هؤلاء الذين دفنوا () (1).

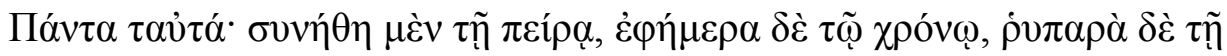

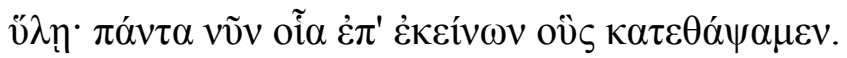

لقد كان ماركوس أوريليوس من أبرز وأنبل أباطرة الرومان، رحيما، خيرا، متسامحا؛ حتى

شبهه بعضهم بالسيد المسيح وعرف الكثير عنه من المسيحيين الأوائل، فقد كانت المسيحية في طريقها إلى الانتشار والازدهار إبان القرن الثاني (2).

لقد أقبل ماركوس أوريليوس على الحكم بدافع الإحساس بالواجب واختيارا لعزيمته في

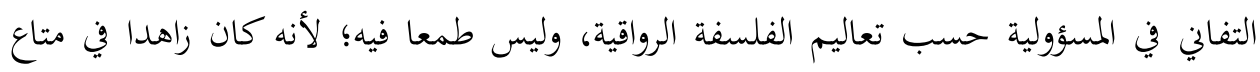
الدنيا (3)

لقد بذل ماركوس أوريليوس جهدا كبيرا في مواجهة الظروف الصعبة بسبب بهاظة تكلفة حروب الباريثين من ناحية وقبائل الشمال من ناحية أخرى، فضلا عن انتشار وباء الطاعون وما سببه من ذعر ونقص في الرجال وتدهور الحالة الاقتصادية، في وقت لم يجد الإمبراطور المال الكافي لإعداد الجيش لرد الخطر عن آمن الإمبراطورية وسلامتها، فما كان من

1- Marcus Aurelius, book 9, chapter 14, section 1, line 1-2.

2-سيد أحمد على الناصري، تاريخ الإمبراطورية الرومانية السياسي والحضاري، دار النهضة العربية،

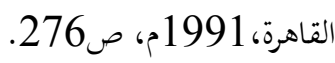

3- Romaine, J.; Marc-Aurèle, ou l'empereur de bonne volonté, Paris, 1968, p. 18.

$$
\text { معظم هذه الأقوال المأثورة التي لا يمكن إغفالها جاءت على شبك الإنترنت في هذه المواقع: }
$$

http://members.aol.com/Heraklit1/marcus.htm

http://classics.mit.edu/Antoninus/meditations.1.one.html

www.fordham.edu/Halsall/ancient/marcusaurelius-anton1.asp

http://myron.sjsu.edu/romeweb/EMPCONT/e081.htm

http://www.knuten.liu.se/ bjoch509/philosophers/hum.html 


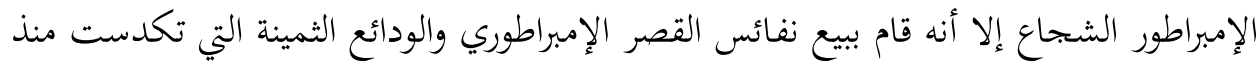

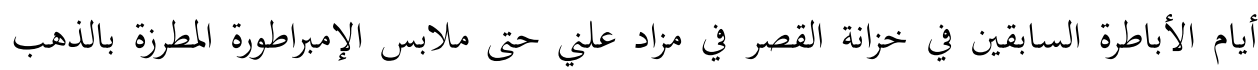
عرضها ماركوس أوريليوس للمزاد (1). لقد طالب بعض الجنود بزيادة الرواتب فأجااكم بصراحة: إن أي زيادة لهم سوف بجيء المباء

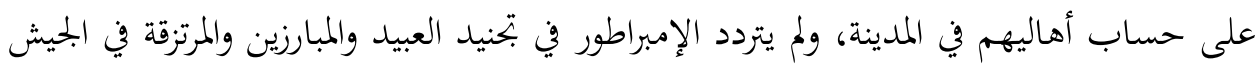

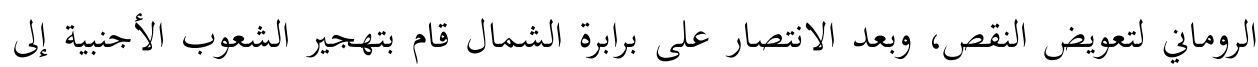

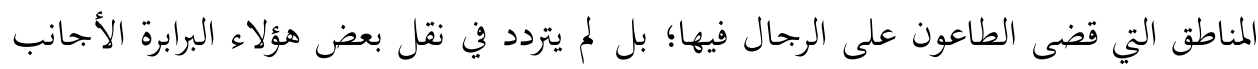

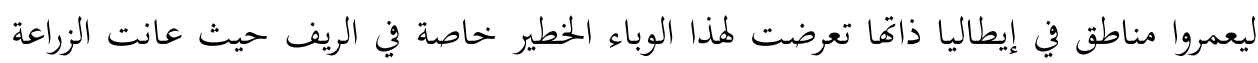
تدهورا كبيرا بسبب النقص في الرجال (2).

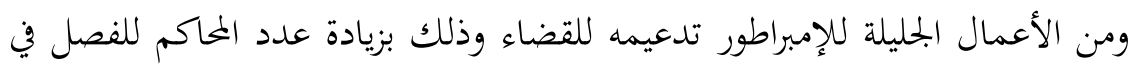

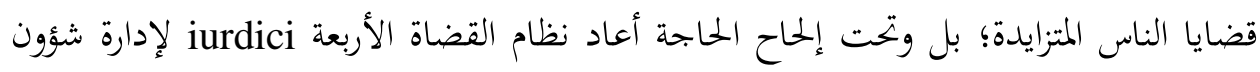

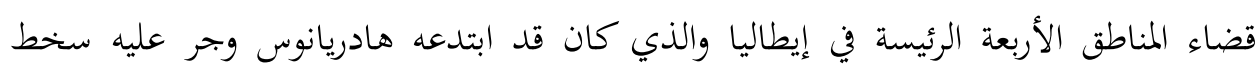

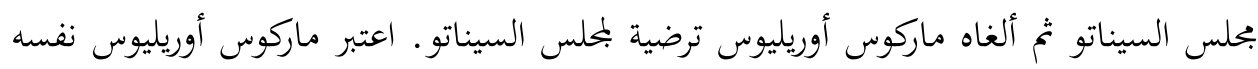

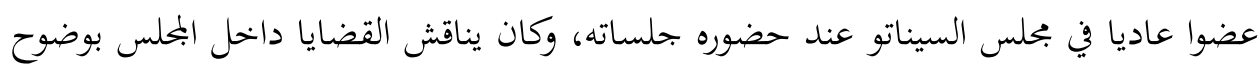

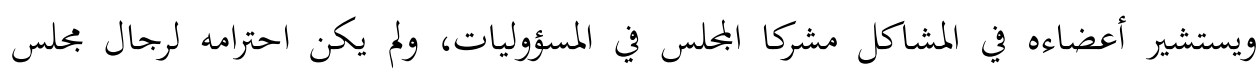

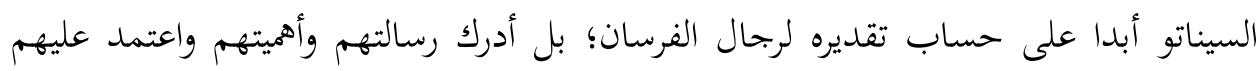

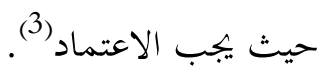

1- Scriptores Historiae Augustae. Vita Marci Antonini Philosophi Iuli Capitolini (Scriptores Historiae Augustae. Vol. 1, ed. E. Hohl, 1965). (2331: 004), Chapter 17, section 4, line 1 to chapter 17 , section 5 , line 1 .

2- هـ. رستوفتزف، تاريخ الإمبراطورية الرومانية الاجتماعي والاقتصادي: ترجمة ومراجعة: زكي على ومحمد

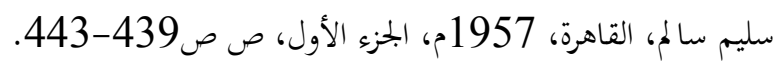

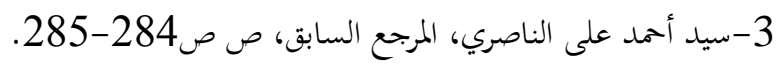


حرص ماركوس أوريليوس على رعاية الفقراء وتوفير الحاجيات لهم من غذاء وترفيه، وفي وقت الأزمات الاقتصادية كان يخفف عن كواهل الناس بإلغاء الضرائب المتأخرة، كما زاد

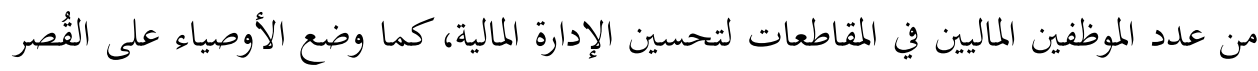
والأيتام من البلوغ حتى سن الخامسة والعشرين تحت إشراف ورقابة خاصة في إدارة ضياع هؤلاء القُصر، كل هذا أكسبه شعبية ومحبة من جميع طوائف الشعب نظرا لمدوئه وبساطته وإنسانيته في

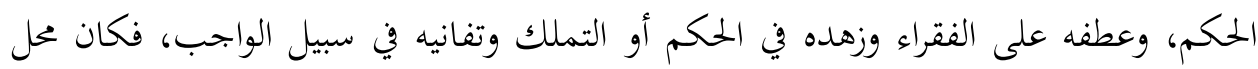
الإعجاب والتقدير من معاصريه ومن الأجيال اللاحقة (1).

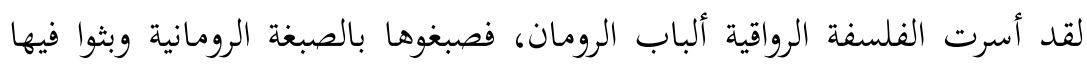
الروح الإنسانية، وتمثلت فيها جميع مراتب المحتمع الروماني وطبقاته، وهكذا أخذت الرواقية تتحول شيئا فشيئا إلى فلسفة عصور الشدة، لقد كان على الفلسفة الرواقية أن تجد الحلول لكل مشاكل هذا العصر، ولم تلبث الفلسفة الرواقية أن أصبحت فلسفة عملية طابعها الجد والصرامة، وهي توائم المزاج الروماني وتتجاوب معه أعظم التجاوب، لقد بثت في نفوس أشياعها الثقة والشجاعة لكي يواجهوا المخاطر في ثبات ورباطة جأث، ولكي يجهروا بآرائهم دون خوف أو وجل، بل وليجابهوا الموت إن لزم الأمر (2).

\section{الحخاتمة:}

يتناول هذا البحث سمات الفلسفة الرواقية في القرن الثاني الميلادي التي تتمثل في شخصية وأفكار الإمبراطور ماركوس أوريليوس، ويبدأ البحث بإعطاء فكرة عن تطور الفلسفة الرواقية عبر العصور وتقسيمها وأشهر الفلاسفة الذين شكلوا المدارس الرواقية وكيف تناولوا

$$
\text { 1- هـ رستوفتزف، المرجع السابق، ص439؛ سيد أحمد على الناصري، مرجع سابق، ص285. }
$$

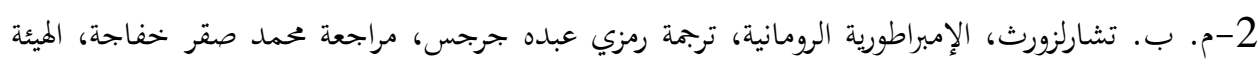

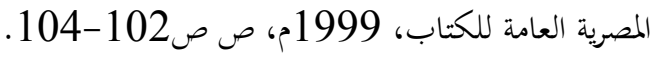


الفلسفة الرواقية حتى وصلت إلى الرومان، وقد أصبح أعظم الفلاسفة الإمبراطور ماركوس أوريليوس في القرن الثاني الميلادي.

كانت أخلاق الرواق عماد العقائد والفضائل الجمهورية في نفوس الكثيرين، وفي عهد الإمبراطورية أوحت الرواقية إلى أنصارها أن يقاوموا استبداد القياصرة، ولكنها كانت مقاومة أخلاقية قبل أن تكون سياسية، وقد جرت الرواقية على أنصارها ألوانا من الأذى والشبهات، إلا أها انتهت بأن اقتحمت أبواب القصر الإمبراطوري شيئا فشيئا؛ إلى أن سيطرت على نفس سيد من سادات العالم الروماني هو الإمبراطور ماركوس أوريليوس. لقد جمع ماركوس أوريليوس بين الفلسفة والسلطة فكان إمبراطورا فيلسوفا، فلم يكن ينسى واجبات الإمبراطور كما لم تفارقه للظة شيمة الفيلسوف؛ ولقد آثر ماركوس أوريليوس الفلسفة على الخطابة، واختار المذهب الرواقي فاعتنقه بصدق وإخلاص، لكن موقف الإمبراطور ماركوس أوريليوس من الرواقية كان موقف القاضي ولم يمثل المدافع عنها، حيث قدم الشكر للإله الذي أعانه على إغفال المنطق والطبيعيات وعدم الأخذ بمسلمات الأمور. وبهذا استطاع هذا الإمبراطور أن يبرر بعض خصائص تلك الفلسفة، وقد مست هذه الخصائص قلوب الناس في زمانه، وأصبحت بهذه المثابة آخر رسالة بعث بها العالم القديم إلى الأجيال المقبلة، ولم يكن في رواقيته متشددا ولا جافيا بل كان في مذهبه لين ويسر وإنسانية، وهي خصائص لم تعرفها الرواقية القديمة، وكان يتحاشى ذكر الاصطلاحات الرواقية البحتة فكان قوله أيسر على السمع وفكره أحرى إلى القلوب، وتخلى عن بعض العقائد الرواقية التي لم تكن توافق الإنسانية؛ فقد كان يرى أن ارتكاب الخطيئة ابتغاء للذة أشد من ارتكابها لدفع ألم أو دفع مضرة، ولا بحد في حكمة ماركوس أوريليوس من الثقة والاعتزاز بالنفس ما تستشعره في

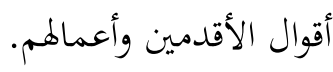


تناول البحث تفسير النظرية الدورية من وجهة نظر الإمبراطور ماركوس أوريليوس، وضرب الأمثال لتوضيح هذه النظرية، وقد توصل الإمبراطور إلى أن الأسباب النهائية لأحداث التاريخ يسلم بثلاثة أسباب محتملة وهي:

$$
\text { 2. } 1 \text { كل شل شيء وليد الصدفة المحضة. }
$$

3. كل شيء باستثناء ما يعود إلى حرية الإنسان يرتكن إلى عناية شفوقة ورحيمة

لقد اقتنع ماركوس أوريليوس بالنظرية التي تقول إن جميع الأشياء في النهاية واحدة، وإن الإنسان يعيش لا في فوضى وعماء، بل في عالم مرتب منظم، فيذكر أن الأشياء كلها متسلسلة متشابكة وكأنما قد ربطت برباط مقدس وثيق، ويمكن القول إنه لا شيء غريب عن الأشياء الأخرى؛ لأنما جميعا قد رتبت معا، وهي تتعاون على تحقيق ما في العالم الواحد من حسن النظام، وذلك أن العالم المؤلف من جميع الأشياء واحد، والإله الملازم في كل مكان والمسيطر على الجميع واحد، والمادة والكون واحد، والقانون واحد، والعقل الشائع في جميع الموجودات العاقلة واحد، وكذلك العقيدة واحدة؛ لأن الحقيقة هي كمال الموجودات التي هي من أسرة واحدة والتي منحت عقلا واحدا.

ثم تناول البحث مواقف ماركوس أوريليوس الدينية والدنيوية، فكثيرا ما يلجأ الإمبراطور إلى البراهين الرواقية لإثبات وجود الإله الواحد، ولكن سرعان ما يبدو أن استمساكه بالدين المقرر لم يكن قائما على حجج فلسفية، ويتجلى في بحثه لهذه المسألة شيء من الحماسة وحرارة العقيدة، إذا صح أن الآلمة لا تمتم بشيء ولا تفكر في شيء، ومثل هذا الاعتقاد زيغ وضلال: 
فلتترك إذن الأضاحي والصلوات والنذور والشعائر الأخرى التي نتمثل بها في أذهاننا حضور الآلمة وقربها من حياتنا.

يوضح البحث أخلاقيات ماركوس اوريليوس، فدائما يدعو إلى طيبة القلب واستقامة الضمير ولنستمع إليه وهو يؤكد أنه على الإنسان أن يبقى بسيطا، طيبا نقي السريرة، جادا، عدوا للزهو والجاه، صديقا للعدالة والحكمة، متدينا، رفيقا إنسانيا، مستمسكا بأداء الواجب، وليجاهد نفسه لكي تبقى كما تريده الفلسفة أن يكون، وليسبح الإله، وليكن دائما في عون الناس، فالحياة قصيرة، وثمرة وجود هذا الإنسان على الأرض أن يصون نفسه مطهرة، وأن يفعل ما يعود بالخير على الجماعة. ويظهر من ثنايا كتاب الإمبراطور ماركوس أوريليوس آثار الانقباض والعبوس، فلقد تعلم من إبيكتيتوس مبادئ الاستسلام والإذعان، ولكنه لم ينظر إلى العالم نظرة الفرح والابتهاج تلك النظرة التي بتعل الحكيم يشعر بأنه ملك ولو كان عبدا، لكن من خواطره يظهر انه يشعر بعبوديته وأنه من رعايا الكون، فهو لم يرد أن يخالف الناموس العام أو يخرج على النظام الكوني، ولكن يخيل إلينا أن نغمته الحزينة لا تشعر بأنه كثير الابتهاج بالإسهام والتعاون الفعال في ذلك العالم، إن ماركوس أوريليوس يمثل الرواقية حين صبغها اضمحلال روما بلون قاتم، ويطلب ماركوس أوريليوس من الإنسان عدم تحقير الموت؛ لأن الموت جزء من الأشياء التي تطلبها الطبيعة.

ومن خلال كتابات ماركوس أوريليوس يظهر أنه يدعو إلى المساواة بين الناس، فهم جميعا متساوون، ولمم من العقل أنصبة متساوية، وهم من أجل هذا يحبون الاجتماع؛ ذلك أن الموجودات كلما ارتفعت في المنزلة زاد ائتلافها وابنذابها بعضها إلى بعض، فينبغي إذن على 
الناس بحسب قانون الطبيعة أن يتحابوا وأن يتواصلوا ، وهم مندوبون إلى أن يتعاونوا أوثق التعاون في سبيل العمل الشامل والخير العام.

ويحث الإنسان على الصبر على البلوى لأها زائلة بسرعة، ويحفز الإنسان على

الاستفادة من وقت الفراغ وعدم قضائه فيما لا ينفع وأن ينظر الإنسان فيما يفعل جيدا. ويبدو مما سبق أن كل ما يدعو إليه ماركوس أوريليوس من فضائل وتحمل للمشاق

والصعاب يعتمد على العقل، وعلى هذا فالعقل ذو أهمية بالغة، ويشبهه بالسهم، فعندما يدور العقل حول التأمل فإنه يندفع للأمام مثل السهم. 

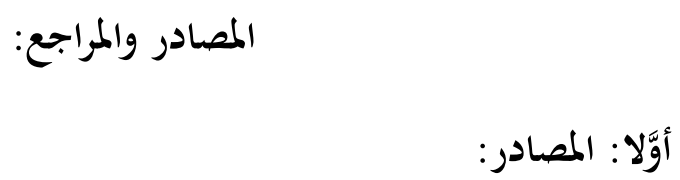

1- Diogenes Laertus, Vitae philosophorum, Trans. by R. D. Hicks, 2 vols, New introduction by H. S. Long, (L.C.L), London, 1925.

2- Epictetus Phil., Dissertationes ab Arriano digestae, LOEB Classical Library, Trans. by W. A. Oldfather, (L.C.L), London, 1989.

3- Iustinianus, Digesta Iustiniani, Book 1, ch. 1, par 10, Sec. 2.1.1.

4- M. Cornelius Fronto, ed. and trans. by C. R. Haines, 2 vols., (L.C.L), London, 1925.

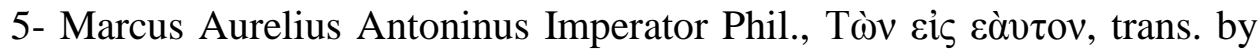
C. R. Haines, 2 vols., (L.C.L), London, 1924.

6- Scriptores Historiae Augustae, Trans. by D. Magie, 3 vols., (1.C.L), London, 1991.

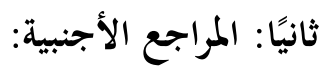

1- Champlin, E.; Fronto and Antonine Rome, Cambridge, 1980.

2- La ferriere, I. F., " Mémoire concernant l' influence du Stoïcisme sur la doctrine des jurisconsultes romains" dans Mémoires de l' Académie des Sciences Morales et Politiques, t. x., Paris, 1860.

3- Long, G., Marcus Aurelius, Meditations, Indiana, 1956.

4- Moreau, J., Stoicisme, Epicurisme, Tradition Hellenique, Paris, 1979.

5- Renan, F., Marc-Aurele et la fin du monde antique, 1882 .

6- Romaine, J.; Marc-Aurèle, ou l'empereur de bonne volonté, Paris, 1968.

7- Vernon, Arnold, Roman Stoicism, New York, 1958. 


\section{ثالثا: مواقع شبكة الإنترنت: - مإن}

1- http://classics.mit.edu/Antoninus/meditations.1.one.html

2- http://members.aol.com/Heraklit1/marcus.htm

3- http://myron.sjsu.edu/romeweb/EMPCONT/e081.htm

4- http://www.knuten.liu.se/ bjoch509/philosophers/hum.html

5-www.fordham.edu/Halsall/ancient/marcusaurelius-anton1.asp

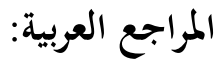

1 - ألبان ويدجري، التاريخ وكيف يفسرونه من كنفوشيوس إلى توينبي، ترجمة: عبد العزيز توفيق

جاويد، الهيئة المصرية العامة للكتاب، القاهرة، 1972م.

2- سيد أحمد على الناصري، تاريخ الإمبراطورية الرومانية السياسي والحضاري، دار النهضة

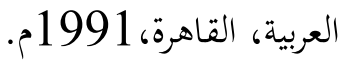

3- عثمان أمين، الفلسفة الرواقية، القاهرة، 1945م.

4- م. ب. تشارلزوث، الإمبراطورية الرومانية، ترجمة رمزي عبده جرجس، مراجعة محمد صقر خفاجة، الهيئة المصرية العامة للكتاب، 1999م.

5- مصطفى النشار، من التاريخ إلى فلسفة التاريخ، "قراءة في الفكر التاريخي عند اليونان"، القاهرة، 1997م.

6- هـ. رستوفتزف، تاريخ الإمبراطورية الرومانية الاجتماعي والاقتصادي: ترجمة ومراجعة: زكي على ومحمد سليم سالم، القاهرة، 1957م، الجزء الأول. 